\title{
The prevalence and predisposing factors of mastitis in lactating mothers in puerperium
}

\author{
Ruma Dutta, Ravikanth Onkarappa Gowder \\ Correspondence: Ravikanth Onkarappa Gowder, Associate Professor, Dept. of Obstetrics \\ and Gynaecology, K.V.G Medical College and Hospital, Sullia, Rajiv Gandhi University Of \\ Health Sciences, Karnataka, India; Email - drravikanthgo@gmail.com
}

Distributed under Creative Commons Attribution-Share Alike 4.0 International.

\begin{abstract}
Objectives: To study the prevalence, evaluate the predisposing factors and know the etiological factors associated with mastitis in lactating mothers during puerperium. Materials and methods: A prospective study was performed from January $1^{\text {st }}, 2014$ to December $31^{\text {st }}, 2015$. Data were collected from patients admitted in the postnatal ward with benign breast problems by preformatted questionnaires. Breast milk cultures were done to evaluate the etiological factors. Data were analyzed by using descriptive statistics. Results: The overall prevalence of puerperal mastitis among lactating mothers was 5.1\%, high among caesarean section patients (5.8\%) compared to vaginally delivered patients $(4.8 \%)$. The predisposing factors include primipara $(57 \%)$, unbooked cases $(57 \%)$, low socioeconomic status $(49 \%)$, anemic patients $(45 \%)$, breast engorgement $(75 \%)$, cracked nipple (44\%), retracted/flat/inverted nipple (13\%), poor attachment of baby to breast $(32 \%)$, infrequent removal of milk (7\%), oversupply of breast milk (37.5\%) and lower supply of breast milk(12.5\%). Breast milk culture reports yielded growth of Staphylococcus aureus (75\%) and MRSA (25\%). Seven patients developed breast abscess (4.4\%). Conclusion: It is recommended to educate the mothers and the family on the exclusive breast feeding practice and its benefits, demand feeding, optimal positioning and attachment of the baby, to provide adequate emotional support and access to skilled help in the early postpartum period.
\end{abstract}

Keywords: Puerperium, mastitis, lactation.

Mastitis is defined as inflammation of the mammary gland. Mastitis is an acute, debilitating condition that occurs in approximately $20 \%$ of breastfeeding women who experience a red, painful breast with fever ${ }^{1,2}$. Two mode of infection, firstly involving the parenchymatous breasts tissues which may lead to cellulitis. The lacteal system remains unaffected. Secondly, infection gains access through the lactiferous duct leading to development of primary mammary adenitis. Almost always from nursing infant's nose and throat, the organism enters the breast through the nipple at the site of a fissure or abrasion. In superficial cellulitis, the onset is acute during first 2-4 weeks postpartum. There may be inflammation preceded by engorgement, fever $\left(102^{\circ} \mathrm{F}\right.$ or more) with chills, tachycardia, flu like symptoms like generalized malaise, headache, nausea, vomiting, sudden onset of intense breast pain. Breast abscess usually occurs as a complication of mastitis ${ }^{3}$.

\section{Materials and Methods}

This study was conducted among 3117 postnatal

Received: $24^{\text {th }}$ January 2018. Accepted: $17^{\text {th }}$ April 2018.

Dutta R, Gowder RO. The prevalence and predisposing factors of mastitis in lactating mothers in puerperium. The New Indian Journal of OBGYN. 2018; 5(1): 28-32. 
lactating mothers who had a full term or preterm, vaginal or caesarean delivery at K.V.G medical college \& Hospital, Sullia, Karnataka, from January $1^{\text {st }} 2014$ to December $31^{\text {st }} 2015$, for a period of six weeks postpartum. Out of 3117 number of delivery, 160 mothers developed mastitis. Data were collected from patients admitted in the postnatal ward with benign breast problems like cracked nipple or sore nipple, breast engorgement, retracted nipple, flat nipple or inverted nipple, poor attachment of baby to the breasts leading to nipple damage, infrequent removal of milk, breast milk amount (normal/low supply/over supply) and breast abscess by preformatted questionnaires and local examination of breasts. Breast milk cultures were done to evaluate the etiological factors. The exclusion criteria of our study were history of mastitis prior to delivery and continued in the postnatal period. Data were analyzed by using descriptive statistics and other appropriate statistical methods.

\section{Results}

The overall prevalence of puerperal mastitis in lactating mothers in this study was $5.1 \%$. Out of 2084 vaginally delivered patients, 100 patients developed puerperal lactational mastitis, the incidence was $4.8 \%$.

Table 1: Demographic Data $(\mathrm{N}=160)$

\begin{tabular}{lll}
\hline Categories & & $\begin{array}{l}\text { Number } \\
(\%)\end{array}$ \\
\hline Booked patients & & $69(43 \%)$ \\
Unbooked patients & & $91(57 \%)$ \\
Primipara & & $91(57 \%)$ \\
Age in years & $18-23$ & $45(28 \%)$ \\
& $24-30$ & $88(55 \%)$ \\
& $>30$ & $27(17 \%)$ \\
Mean age & 27 yrs; range 18-36yrs & \\
Socioeconomic & Upper & $13(8 \%)$ \\
status (According & Upper middle & $5(3 \%)$ \\
to Kuppuswamy & Lower middle & $64(40 \%)$ \\
classification) & Upper lower & $78(49 \%)$ \\
\hline
\end{tabular}

Out of 1033 patients, who underwent cesarean section, 60 patients developed puerperal lactational mastitis, the incidence was 5.8\%. Among the 160 puerperal lactational mastitis patients, primipara were $91(57 \%)$ and multipara were 69 (43\%) (Table 1). The mean age of the women was 27 years (Range 18 to 36 years) (Table 1). The distribution of patients who developed puerperal mastitis in relation to period of gestation $<37$ weeks, 37- 40weeks and $>$ 40weeks were 20(12.5\%), $130(81.25 \%)$ and $10(6.25 \%)$ respectively. In this study, lactational mastitis was found to be more in low socioeconomic status group (49\%) and unbooked cases (57\%) (Table 1).

The predisposing factors of lactational mastitis in this study was breast engorgement (75\%), anemia (45\%),

Table 2: Predisposing factors which might lead to puerperal mastitis among lactating mothers $(\mathrm{N}=160)$

\begin{tabular}{|c|c|}
\hline Risk factors & No of cases $(\%)$ \\
\hline Primi parity & $91(57 \%)$ \\
\hline Low socio-economic status & $78(49 \%)$ \\
\hline Anemia & $72(45 \%)$ \\
\hline Breast engorgement & $120(75 \%)$ \\
\hline Cracked nipple & $70(44 \%)$ \\
\hline Retracted nipple & $21(13 \%)$ \\
\hline Poor attachment of baby to breast & $51(32 \%)$ \\
\hline Infrequent removal of milk & $51(32 \%)$ \\
\hline Breast milk Normal & $80(50 \%)$ \\
\hline Over supply & $60(37.5 \%)$ \\
\hline Low supply & $20(12.5 \%)$ \\
\hline
\end{tabular}

cracked nipple (44\%), poor attachment of baby to the breasts $(32 \%)$, over supply of breast milk (37.5\%) and lower supply of breast milk (12.5\%) respectively (Table $2)$. Out of 72 anemic patients, 13 (8\%) had mild, 40 $(25 \%)$ had moderate and $19(12 \%)$ patients had severe anemia.

Breast milk culture report of mastitis yielded growth of Staphylococcus aureus in 120 (75\%) patients and MRSA (Methicillin resistance Staphylococcus aureus) in $40(25 \%)$ patients. The prevalence of breast abscess in our Table 3: Breast milk culture report of patients

\begin{tabular}{lcc}
\hline Breast milk culture & $\begin{array}{l}\text { Mastitis } \\
(\mathbf{N}=\mathbf{1 6 0})\end{array}$ & $\begin{array}{l}\text { Breast } \\
\text { abscess (N=7) }\end{array}$ \\
\cline { 2 - 3 } & Number (\%) & Number (\%) \\
\hline Staphylococcus aureus & $120(75 \%)$ & $5(71 \%)$ \\
MRSA & $40(25 \%)$ & $2(29 \%)$ \\
\hline
\end{tabular}

study was $4.4 \%(7 / 160)$ (Table 3$)$. In one of the patients with breast abscess, one liter of pus which was drained with radial incision made over the breast. Breast Abscess milk culture yielded growth of Staphylococcus aureus and MRSA.

\section{Discussion}

Mastitis is defined as at least two breast signs or symptoms (pain, redness or lump) and one systemic 
symptom (fever or 'flu-like symptoms) present for at least twelve hours ${ }^{4}$. Mastitis is reported to occur in $2-24 \%$ of breastfeeding women from several weeks up to one year after delivery in women who continue to breastfeed ${ }^{5}$. It is most common in the first 6 weeks of breastfeeding with the highest incidence occurring during the second and third weeks. It is initially localized to one segment of the breast, but if untreated, can spread to affect the whole breast $^{6,7}$.

We studied 3117 postnatal lactating mothers in puerperium, out of which 160 mothers developed mastitis. The prevalence of mastitis among lactating mothers in the first six weeks of postpartum period in the present study is $5.1 \%$. The prevalence of mastitis varies depending on the definition and the number of weeks postpartum ${ }^{5}$. For example: A community based study among rural women of Rajasthan by Iyengar $\mathrm{K}$ reported the incidence of mastitis was $1.3 \%$ during first week after delivery ${ }^{5}$. A prospective cohort study conducted in western Nepal reported the incidence of mastitis was $8.0 \%$ in the first month postpartum ${ }^{8}$. The CASTLE study, a prospective cohort study which recruited nulliparous women in late pregnancy in two maternity hospitals in Melbourne, Australia reported $20 \%$ (70/346) of participants developed mastitis during the first eight weeks postpartum ${ }^{2}$. The incidence rate of $9.5 \%(\mathrm{n}=946)$ was reported for a cohort of women followed up for 3 months in the United States ${ }^{8}$. A descriptive study of mastitis in Australian breastfeeding women reported a 6 month incidence rate of $17 \%(\mathrm{n}=$ 206) of women experienced mastitis, of which 53\% cases occurred in first 4 weeks postpartum ${ }^{1}$. A prospective cohort study of mastitis among out of 670 Chinese breastfeeding mothers, 42 women $(6.3 \%)$ experienced at least one episode of mastitis during the first 6 months after delivery ${ }^{8,9}$. Scott et al. reported a 6-month incidence of $18 \%$ among a Scottish cohort, of which $53 \%$ of the cases (30 of 57) occurred in the first 4 weeks postpartum ${ }^{10}$. Vogel et al. reported a 12-month incidence rate of $23.7 \%(\mathrm{n}=350)$ among a cohort of women in New Zealand ${ }^{8}$. The lower incidence of puerperal mastitis among lactating mothers in our study could be due to two reasons: firstly, exclusive breastfeeding is universal in our study area and secondly, we collected data only up to six weeks after delivery.
The incidence of lactational mastitis was lower among the vaginal delivery patients $(4.8 \%)$ compared to patients who underwent cesarean section $(5.8 \%)$ in our study. Prelacteal feeding and cesarean section were associated with a higher likelihood of mastitis ${ }^{8}$. A negative association between Caesarean delivery and breastfeeding exists because postoperative care routines delay the onset of lactation, disrupt mother infant interaction and inhibit infant suckling ${ }^{11}$. Mothers who had cesarean section were more likely to have problems related to breastfeeding, including nipple fissure, in comparison to women who had vaginal delivery 12,13 . However, there were no relationships observed between nipple injuries with the type of childbirth in a cohort study conducted in Australia with 340 primiparous women ${ }^{14}$.

In our study, mean age was 27 years of age (Range 18 to 36 years). The majority of the women were between 24-30 years (55\%). Maternal age is not directly linked to lactational mastitis; however, there is evidence that young women find it more difficult to breastfeed due to insecurity and inexperience. This can lead to difficulty in breastfeeding, culminating in breast problems and consequently in early weaning ${ }^{15}$.

In our study, higher percentage of lactational mastitis was found in primiparous women $(57 \%)$ compared to multiparous women (43\%).Our study is similar to Viduedo AFS et al, reported higher percentage (64\%) of severe lactational mastitis among young primiparous women ${ }^{16}$. The binational study also reported mastitis more common in primiparous women ${ }^{17}$. Women who never breastfed may be more anxious and, as a result, this may interfere with the breastfeeding process ${ }^{16}$.

Out of 160 mastitis patients, 72 women were anemic. According to ICMR classification, 13 patients had mild anemia, 40 patients had moderate anemia and 19 patients had severe anemia. Anemic women might be more vulnerable to infection.

Risk factors that have been suggested to be strongly associated to mastitis include cracked or sore nipples, use of ointments, inappropriate breastfeeding practices, mastitis with a previous child, and peripartum antibiotic therapy ${ }^{1,7}$. The present study is similar to various other studies, cracked nipple or sore nipple were associated with mastitis under the hypothesis that it provides a portal 
of entry for microorganisms $1,2,4,9,18$.

Regarding the amount of milk produced, milk over or undersupply versus normal supply that mastitis may arise from a higher milk supply because of the risk of milk stasis, if the infant delays or misses feeds, this situation may provide good conditions for bacterial overgrowth. On the other hand, low milk supply could give to the mother a false perception of low milk production when, actually, only secretion is compromised due to the formation of thick bacterial biofilms inside the milk ducts ${ }^{1,2,18,19}$.

The incorrect handling of the infant to the mother's breast and the inadequate positioning between mother and child were associated to nipple trauma. Prevention of nipple damage is likely to reduce the incidence of infectious mastitis. New mothers need good advice about optimal attachment of the baby to the breast and access to skilled help in the early postpartum days and weeks ${ }^{13,20,}$ 21

Breast milk culture report of mastitis yielded growth of Staphylococcus aureus in 120 (75\%) patients and MRSA in $40(25 \%)$ patients. Seven patients with mastitis developed breast abscess, the incidence was $4.4 \%$ (7/160) as complication. The literature shows that the incidence of breast abscess in lactating mothers varies between $3 \%$ and $11 \%{ }^{6,18,24}$. In one of the patients with breast abscess, one liter of pus was drained with radial incision made over the breast. Breast Abscess milk culture yielded growth of MRSA and Staphylococcus aureus. The most common bacterium found in breast abscess secretion culture was Staphylococcus aureus, which coincides with our findings 15, 23-28. Various other studies also reported MRSA in breast abscess secretion culture which is similar to our study ${ }^{25,27}$. A lactational breast abscess is usually bacterial in etiology and can be effectively managed with oral antibiotics. All patients in our study received antibiotics based on their sensitivity pattern and were discharged in 3 to 4 days. In addition to antibiotics, management of breast abscess included incision and drainage, symptomatic treatment with analgesia and antipyretics, reassurance, assessment of the infant's breastfeeding technique, education, emotional support, and support for continuous breastfeeding.

\section{Conclusion}

It is recommended to educate the mothers and the family on the exclusive breast feeding practice and its benefits, demand feeding, optimal positioning and attachment of the baby, to provide adequate emotional support and access to skilled help in the early postpartum period. Continued breastfeeding should be encouraged in the presence of mastitis which generally does not pose a risk to the infant. Breast abscess is the most common complication of mastitis. It can be prevented by early treatment of mastitis and continued breastfeeding.

\section{Conflict of interest: None. Disclaimer: Nil.}

\section{References}

1.Amir LH, Forster DA, Lumley J and McLachlan H. A descriptive study of mastitis in Australian breastfeeding women: incidence and determinants. BMC Public Health. 2007; 7: 62 .

2.Cullinane M, Amir L, Donath SM. Determinants of mastitis in women in the CASTLE study: a cohort study. BMC Family Practice. 2015; 16: 181.

3.Konar H. Abnormalities of the Puerperium. In: Konar H, editor. DC Dutta's Textbook of Obstetrics. 8thed. New Delhi: Jaypee; 2015: p500-13.

4.Amir LH, Garland SM, Lumley J. A case-control study of mastitis: nasal carriage of Staphylococcus aureus. BMC Family Practice. 2006; 7: 57.

5.Iyengar K. Early Postpartum Maternal Morbidity among Rural Women of Rajasthan, India: A Community-based Study. J Health Popul Nutr. 2012 Jun; 30(2): 213-25.

6.Cusack L, Brennan M. Lactational mastitis and breast abscess: diagnosis and management in general practice. Aust Fam Physician. 2011; 40(12): 976.

7.Spencer JP. Management of mastitis in breastfeeding women. Am Fam Physician. 2008 sep 15; 78(6): 727-31.

8. Khanal V, Scott JA, Lee AH, Binns CW. Incidence of Mastitis in the Neonatal Period in a Traditional Breastfeeding Society: Results of a Cohort Study. Breastfeeding Medicine. 2015; 10(10). 481-7.

9.Tang L, Lee AH, Qiu L, Binns CW. Mastitis in Chinese breastfeeding mothers: a prospective cohort study. Breastfeed Med. 2014 Jan-Feb; 9(1): 35-8.

10.Scott JA, Robertson M, Fitzpatrick J, Knight C, Mulholland S. Occurrence of lactational mastitis and medical management: A prospective cohort study in Glasgow. Int Breastfeed J. 2008; 3: 21.

11.Prior E, Santhakumaran S, Gale C, Philipps LH, Modi N, Hyde MJ. Breastfeeding after cesarean delivery: a systematic 
review and meta-analysis of world literature. Am J Clin Nutr. 2012; 95: 1113-35.

12.Boskabadi H, Ramazanzadeh M, Zakerihamidi M, Rezagholizade OF. Risk factors of breast problems in mothers and its effects on newborns. Iran Red Crescent Med J. 2014; 16 (6): e8582.

13.Silva DJ, de Oliveira VT, Oliveira VG. Factors associated to nipple trauma in lactation period: a systematic review. Rev Bras Saude Mater Infant. 2017 Mar;17(1): 27-42.

14.Buck ML, Amir LH, Cullinane M, Donath SM. Nipple pain, damage, and vasospasm in the first 8 weeks postpartum. Breastfeed Med. 2014; 9 (2): 56-62.

15.Kinlay JR, O'Connell DL, Kinlay S. Risk factors for mastitis in breastfeeding women: results of a prospective cohort study. Aust N Z J Public Health. 2001; 25: 115-20.

16.Viduedo AFS, Leite JRC, Monteiro JCS, Reis MCG, Gomes-Sponholz FA. Severe lactational mastitis: particularities from admission. Rev Bras Enferm. 2015; 68(6): 806-11.

17.Iatrakis G, Zervoudis S, Ceausu I, Peitsidis P, Tomara I, Bakalianou K, Hudita D. Clinical features and treatment of lactational mastitis: the experience from a binational study. Clin Exp Obstet Gynecol. 2013; 40(2): 275-6.

18. Mediano P, Fernández L, Rodríguez JM, Marín M. Case control study of risk factors for infectious mastitis in Spanish breastfeeding women. BMC Pregnancy and Childbirth. 2014; 14: 195

19.Delgado S, Arroyo R, Jiménez E, Marín ML, del Campo R, Fernández L, Rodríguez JM. Staphylococcus epidermidis strains isolated from breast milk of women suffering infectious mastitis: potential virulence traits and resistance to antibiotics. BMC Microbiol. 2009; 9: 82.

20.Kronborg H, Vaeth M. How Are Effective Breastfeeding Techniqueand Pacifier Use Related to Breastfeeding Problems and BreastfeedingDuration? Birth. 2009; 36: 3442.

21.Goyal RC, Banginwar AS, Ziyo F, Toweir AA. Breastfeeding practices: Positioning, attachment (latch-on) and effective suckling-A hospital-based study in Libya. $\mathrm{J}$ Fam Comm Med. 2011; 18 (2): 74-9.

22.Bertrand H, Rosenblood LK. Stripping out pus in lactational mastitis: a means of preventing breast abscess. Can Med Assoc J. 1991; 145: 299-306.

23.Kvist LJ, Larsson BW, Hall-Lord ML, Steen A, Schalen C. The role of bacteria in lactational mastitis and some considerations of the use of antibiotic treatment. Int Breastfeed J. 2008; 3: 6.

24.Amir LH, Forster D, McLachlan H, Lumley J. Incidence of breast abscess in lactating women: report from an Australian cohort. BJOG. 2004; 111(12): 1378-81.

25.Ramakrishnan R, Trichur RV, Murugesan S, Cattamanchi $\mathrm{S}$. Analysis of the microbial flora in breast abscess: a retrospective cohort study conducted in the emergency department. Int Surg J. 2017; 4: 2143-7.

26.Sandhu GS, Gill HS, Sandhu GK, Gill GP, Gill AK. Bacteriology in breast abscesses. Sch J App Med Sci. 2014; 2(4E): 1469-72.

27.Chick JFB, Chauhan NR, Polen LA. Emergency management of puerperal breast abscess. Intern Emerg Med. 2012; 7(2): S167-S168.

28.Kataria K, Srivastava A, Dhar A. Management of Lactational Mastitis and Breast Abscesses: Review of Current Knowledge and practice. Indian J Surg. 2013NovDec; 75(6):115-20.

\section{Ruma Dutta ${ }^{1}$, Ravikanth Onkarappa Gowder ${ }^{2}$ \\ ${ }^{1}$ Senior Resident, Dept. of Obstetrics and Gynaecology, Aditya Diagnostics and Hospital, Dibrugarh, Assam, India; ${ }^{2}$ Associate Professor, Dept. of Obstetrics and Gynaecology, K.V.G Medical College and Hospital, Sullia, Karnataka, India.}

